\title{
Estudo das condições de crescimento do Rhodococcus erythropolis ATCC 1277
}

\author{
DANIELA GIER DELLA ROCCA ${ }^{1}$, DIEGO TODESCATO ${ }^{1}$, DANIELLE MAASS ${ }^{1}$, \\ DÉBORA OLIVEIRA, SELENE M. A. GUELLI U. DE SOUZA ${ }^{1, *}$, ANTÔNIO AUGUSTO \\ U. DE SOUZA ${ }^{1}$
}

${ }^{1}$ Laboratório de Transferência de Massa, Departamento de Engenharia Química e Engenharia de Alimentos, Universidade Federal de Santa Catarina, PO Box 476, CEP 88040-900 Florianópolis, SC, Brasil

Telefone para contato: (+55) (48) 3721-9448; Fax: (+55) (48) 3721-9687

E-mail para contato: augusto@enq.ufsc.br

\begin{abstract}
RESUMO - A capacidade da bactéria Rhodococcus erythropolis de degradar compostos sulfurados tem feito com que ela seja amplamente utilizada em diversos processos, tanto na área biotecnológica industrial, quanto na área ambiental - principalmente no que diz respeito aos problemas relacionados à chuva ácida. $\mathrm{O}$ interesse em se direcionar um estudo preliminar sobre o meio de crescimento e sobre as condições de cultivo desta bactéria tem por objetivo obter um meio nutritivo eficiente; mas que, ao mesmo tempo, seja economicamente viável aos processos industriais, tendo-se como possibilidade substituir os substratos usados neste estudo por compostos naturais e que visem à sustentabilidade, tais como o bagaço da cana-de-açúcar. Para tanto, buscou-se aprimorar o meio de cultivo do micro-organismo $R$. erythropolis ATCC 4277, através de um planejamento experimental $2^{(6-1)}$. Optou-se por variar as concentrações dos constituintes do seu caldo nutritivo (glicose, extrato de malte, extrato de levedura, $\mathrm{CaCO}_{3}$ ), além da temperatura e da agitação. A partir dos resultados, foi possível concluir que as concentrações de glicose e malte não são consideradas estatisticamente relevantes, enquanto que as demais variáveis são significativas. Desses fatores, a agitação e o extrato de levedura possuem efeito positivo, inverso ao do resultado obtido para o $\mathrm{CaCO}_{3}$ e para a temperatura, que têm efeito negativo sobre o crescimento do $R$. erythropolis. É relevante, ainda, destacar o efeito positivo sobre o crescimento das bactérias da interação entre o extrato de levedura e a agitação.
\end{abstract}

\section{INTRODUÇÃO}

Atualmente, um dos maiores problemas associados ao petróleo é a emissão de dióxido de enxofre $\left(\mathrm{SO}_{2}\right)$, durante a sua combustão. Esse gás, ao reagir com o vapor d'água atmosférico, gera como produto o ácido sulfúrico $\left(\mathrm{H}_{2} \mathrm{SO}_{4}\right)$ - fenômeno conhecido como chuva ácida, que representa uma questão ambiental de considerável gravidade. Por se tratar de um ácido forte, ele tem alto poder degradante, o que pode vir a afetar o meio ambiente; ocasionando, por exemplo, o surgimento de clareiras e desequilíbrio de sistemas aquáticos 
que não conseguem adaptar-se a maiores níveis do íon hidrônio $\left(\mathrm{H}^{+}\right)$. Além disso, a chuva ácida tem a capacidade de retirar metais pesados do solo, levando-os para sistemas hídricos, fato que pode ocasionar problemas de saúde à população local.

Alternativamente, tem-se estudado a possibilidade de se utilizarem bactérias para a retirada de enxofre dos derivados de petróleo, método conhecido como biodessulfurização. Essa nova maneira tem sido amplamente aceita, por se tratar de um processo de custo reduzido e capaz de romper certos anéis sulfônicos de modo mais efetivo que a hidrodessulforização - injeção de gás hidrogênio $\left(\mathrm{H}_{2}\right)$ nos derivados de combustíveis fósseis. A degradação pela biodessulfurização é realizada por enzimas produzidas por esses microorganismos, que, devido à alta especificidade associada a esses polipeptídeos, degradam apenas os compostos sulfurados, sem afetar as estruturas dos hidrocarbonetos, como na rota dessulfurante do DBT, por exemplo. Ademais, o meio de crescimento utilizado pelas bactérias dessulfurantes não apresenta problemas ambientais vinculados ao seu descarte.

Um microrganismo que vem se destacando pela capacidade de degradar o DBT pela via "4S" é o Rhodococcus sp. pois possui uma característica hidrofóbica, o que faz com que, em um sistema bifásico óleo/água, essa bactéria fique na interface. Outra característica interessante das linhagens de Rhodococcus é a sua capacidade de sobreviver aos efeitos tóxicos de muitos solventes, adaptando sua membrana celular a fim de manter funções biológicas essenciais. Mudanças na composição dos ácidos graxos da membrana, com vistas a manter a mesma fluidez da membrana, parece ser a maior resposta dessa bactéria a compostos altamente tóxicos (HEIPIEPER et al., 1994; CARVALHO et al., 2005a).

Há que se ter em conta, por um lado, o problema da acessibilidade dos microorganismos aos compostos que contêm enxofre e, por outro, mesmo que essa acessibilidade exista à existência de impedimentos estéricos associados à estrutura desses mesmos compostos, que dificultam a atuação dos sistemas enzimáticos microbianos. Alternativamente ao uso de células intactas, a utilização de enzimas livres ou imobilizadas tem sido objeto de patentes para aplicação em processos de biodessulfurização (Kilbane et al, 1994, Kern et al, 1989).

Optou-se por usar a bactéria Rhodococcus erythropolis pelo fato de esses microorganismos serem um dos principais utilizados nos processos de biodessulfurização. Assim, os estudos foram direcionados para a etapa do seu crescimento no meio de cultura. A proposta é de se alcançar a maior quantidade de células com a menor quantidade possível de substratos.

O crescimento dos micro-organismos é um processo dinâmico que requer energia química e nutriente para a síntese dos componentes celulares e a manutenção das células. Para tanto, buscou-se aprimorar a composição do meio de cultura em função das concentrações de extrato de levedura, extrato de malte, glicose, $\mathrm{CaCO}_{3}$, temperatura e agitação.

Os reagentes escolhidos fazem parte do meio Yeast Malt Extract Agar (YMA), optou-se por ele, uma vez que foi sugerido como o melhor meio de manutenção pela própria Fundação Tropical de Pesquisas e Tecnologia "André Tosello". As outras duas variáveis foram escolhidas por serem comprovadamente influentes no crescimento microbiano. A temperatura deve se encontrar em uma faixa ótima, uma vez que, quando inadequada, pode não retirar as bactérias do estado de latência. Já a agitação influencia na quantidade de oxigênio dissolvido no meio de cultivo, por se tratar de um micro-organismo aeróbico seu crescimento é proporcional a esse nível de oxigenação. 


\section{MATERIAIS E MÉTODOS}

\subsection{Inóculo}

O inóculo de $50 \mathrm{~mL}$ foi preparado a partir de extrato de levedura, glicose $\left(\mathrm{C}_{6} \mathrm{H}_{12} \mathrm{O}_{6}\right)$, carbonato de Cálcio $\left(\mathrm{CaCO}_{3}\right)$ e malte $\left(\mathrm{C}_{12} \mathrm{H}_{22} \mathrm{O}_{11}\right)$. A ele foi adicionada uma pequena quantidade de bactérias que permaneceram, por vinte e quatro horas, a uma velocidade de 150 rotações por minuto (rpm) e a uma temperatura de $27^{\circ} \mathrm{C}$ - em fase de adaptação.

\subsection{Meio de crescimento}

Com o intuito de otimizar o meio de crescimento, utilizaram-se os mesmos reagentes do inóculo, mas variaram-se suas concentrações. Primeiramente, transferiu-se $10 \%$ (v/v) do inóculo para outro frasco Erlenmeyer contendo meio de crescimento esterilizado. Neste instante, retirou-se a primeira alíquota do meio de crescimento e leu-se sua absorbância no espectrofotômetro $(\lambda=600 \mathrm{~nm})$. O processo foi repetido até que o crescimento do microorganismo atingisse a fase estacionária. Desta vez, o volume foi de $100 \mathrm{~mL}$ e o período de análise foi fixado em $18 \mathrm{~h}$ (período em que todos os micro-organismos se estabilizaram). Porém, suas velocidades e suas temperaturas foram alteradas dependendo do experimento.

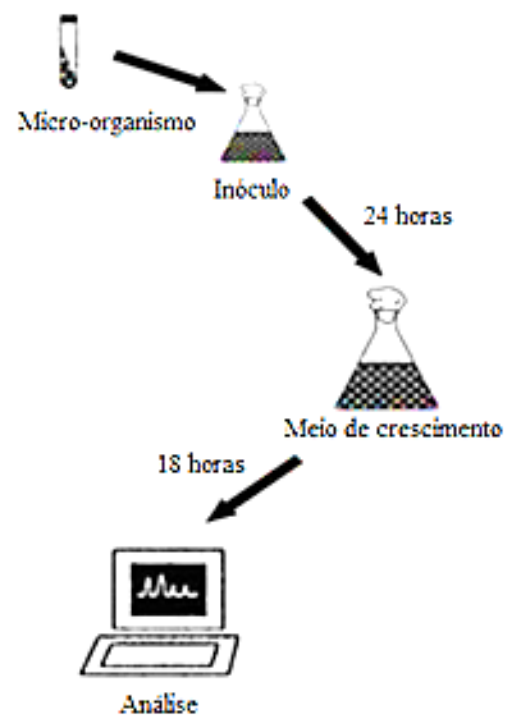

Figura 1 - Resumo da metodologia utilizada

\subsection{Planejamento experimental}


No estudo do processo, em batelada, foram modificadas seis variáveis:

(A) Concentração de levedura (g.L $\left.\mathrm{L}^{-1}\right)$

(B) Concentração de glicose $\left(\mathrm{g} . \mathrm{L}^{-1}\right)$

(C) Concentração de malte $\left(\mathrm{g} . \mathrm{L}^{-1}\right)$

(D) Concentração de carbonato de cálcio $\left(\mathrm{g} \cdot \mathrm{L}^{-1}\right)$

(E) Temperatura $\left({ }^{\circ} \mathrm{C}\right)$

(F) Agitação (rpm)

Por serem seis fatores variáveis, optou-se por se realizarem experimentos no formato $2^{(6-1)}$ com mais quatro replicatas no ponto central, totalizando 36 experimentos. Definiram-se os níveis de variação codificados como $-1,0$ e +1 - para cada um dos fatores em estudo. As variáveis e seus respectivos níveis de variação são mostrados na Tabela 1.

Tabela 1 - Fatores e níveis estudados no planejamento experimental $2^{(6-1)}$.

\begin{tabular}{ccccc}
\hline Fatores & Nível & $\mathbf{- 1}$ & $\mathbf{0}$ & $\mathbf{+ 1}$ \\
\hline $\mathrm{A}$ & Extrato de Levedura $\left(\mathrm{g} \mathrm{L}^{-1}\right)$ & 2,0 & 4,0 & 6,0 \\
$\mathrm{~B}$ & Glicose $\left(\mathrm{g} \mathrm{L}^{-1}\right)$ & 2,0 & 4,0 & 6,0 \\
$\mathrm{C}$ & Extrato de Malte $\left(\mathrm{g} \mathrm{L}^{-1}\right)$ & 5,0 & 10 & 15 \\
$\mathrm{D}$ & $\mathrm{CaCO}_{3}\left(\mathrm{~g} \mathrm{~L}^{-1}\right)$ & 1,0 & 2,0 & 3,0 \\
$\mathrm{E}$ & ${\text { Temperatura }\left({ }^{\circ} \mathrm{C}\right)}_{\mathrm{F}}$ & 24 & 28 & 32 \\
$\mathrm{~F}$ & Agitação $(\mathrm{rpm})$ & 100 & 150 & 200 \\
\hline
\end{tabular}

\section{RESULTADOS E DISCUSSÃO}

Tabela 2 - Planejamento experimental fatorial parcial $2^{(6-1)}$ e as respostas em termos de crescimento celular.

\begin{tabular}{cccccccc}
\hline Exp. & A & B & C & D & E & F & $\begin{array}{c}\text { Crescimento } \\
(\mathbf{g} / \mathbf{L})\end{array}$ \\
\hline 01 & $(-1)$ & $(-1)$ & $(-1)$ & $(-1)$ & $(-1)$ & $(-1)$ & 2,42 \\
02 & $(1)$ & $(-1)$ & $(-1)$ & $(-1)$ & $(-1)$ & $(1)$ & 5,60 \\
03 & $(-1)$ & $(1)$ & $(-1)$ & $(-1)$ & $(-1)$ & $(1)$ & 1,56 \\
04 & $(1)$ & $(1)$ & $(-1)$ & $(-1)$ & $(-1)$ & $(-1)$ & 4,03 \\
05 & $(-1)$ & $(-1)$ & $(1)$ & $(-1)$ & $(-1)$ & $(1)$ & 1,51 \\
06 & $(1)$ & $(-1)$ & $(1)$ & $(-1)$ & $(-1)$ & $(-1)$ & 3,55 \\
07 & $(-1)$ & $(1)$ & $(1)$ & $(-1)$ & $(-1)$ & $(-1)$ & 1,83 \\
08 & $(1)$ & $(1)$ & $(1)$ & $(-1)$ & $(-1)$ & $(1)$ & 5,28 \\
09 & $(-1)$ & $(-1)$ & $(-1)$ & $(1)$ & $(-1)$ & $(1)$ & 1,21 \\
10 & $(1)$ & $(-1)$ & $(-1)$ & $(1)$ & $(-1)$ & $(-1)$ & 0,08 \\
11 & $(-1)$ & $(1)$ & $(-1)$ & $(1)$ & $(-1)$ & $(-1)$ & 0,0
\end{tabular}




\begin{tabular}{lccccccc}
12 & $(1)$ & $(1)$ & $(-1)$ & $(1)$ & $(-1)$ & $(1)$ & 3,94 \\
13 & $(-1)$ & $(-1)$ & $(1)$ & $(1)$ & $(-1)$ & $(-1)$ & 0,0 \\
14 & $(1)$ & $(-1)$ & $(1)$ & $(1)$ & $(-1)$ & $(1)$ & 4,06 \\
15 & $(-1)$ & $(1)$ & $(1)$ & $(1)$ & $(-1)$ & $(1)$ & 0,77 \\
16 & $(1)$ & $(1)$ & $(1)$ & $(1)$ & $(-1)$ & $(-1)$ & 0,91 \\
17 & $(-1)$ & $(-1)$ & $(-1)$ & $(-1)$ & $(1)$ & $(1)$ & 1,14 \\
18 & $(1)$ & $(-1)$ & $(-1)$ & $(-1)$ & $(1)$ & $(-1)$ & 0,0 \\
19 & $(-1)$ & $(1)$ & $(-1)$ & $(-1)$ & $(1)$ & $(-1)$ & 0,96 \\
20 & $(1)$ & $(1)$ & $(-1)$ & $(-1)$ & $(1)$ & $(1)$ & 6,91 \\
21 & $(-1)$ & $(-1)$ & $(1)$ & $(-1)$ & $(1)$ & $(-1)$ & 0,82 \\
22 & $(1)$ & $(-1)$ & $(1)$ & $(-1)$ & $(1)$ & $(1)$ & 5,77 \\
23 & $(-1)$ & $(1)$ & $(1)$ & $(-1)$ & $(1)$ & $(1)$ & 2,28 \\
24 & $(1)$ & $(1)$ & $(1)$ & $(-1)$ & $(1)$ & $(-1)$ & 1,97 \\
25 & $(-1)$ & $(-1)$ & $(-1)$ & $(1)$ & $(1)$ & $(-1)$ & 0,0 \\
26 & $(1)$ & $(-1)$ & $(-1)$ & $(1)$ & $(1)$ & $(1)$ & 0,71 \\
27 & $(-1)$ & $(1)$ & $(-1)$ & $(1)$ & $(1)$ & $(1)$ & 0,0 \\
28 & $(1)$ & $(1)$ & $(-1)$ & $(1)$ & $(1)$ & $(-1)$ & 0,0 \\
29 & $(-1)$ & $(-1)$ & $(1)$ & $(1)$ & $(1)$ & $(1)$ & 0,0 \\
30 & $(1)$ & $(-1)$ & $(1)$ & $(1)$ & $(1)$ & $(-1)$ & 0,0 \\
31 & $(-1)$ & $(1)$ & $(1)$ & $(1)$ & $(1)$ & $(-1)$ & 0,0 \\
32 & $(1)$ & $(1)$ & $(1)$ & $(1)$ & $(1)$ & $(1)$ & 2,28 \\
33 & $(0)$ & $(0)$ & $(0)$ & $(0)$ & $(0)$ & $(0)$ & 2,74 \\
34 & $(0)$ & $(0)$ & $(0)$ & $(0)$ & $(0)$ & $(0)$ & 3,22 \\
35 & $(0)$ & $(0)$ & $(0)$ & $(0)$ & $(0)$ & $(0)$ & 2,29 \\
36 & $(0)$ & $(0)$ & $(0)$ & $(0)$ & $(0)$ & $(0)$ & 1,73 \\
\hline
\end{tabular}

A Tabela 2 mostra a matriz de planejamento fracionário e as respostas obtidas para cada ensaio, avaliando a influência da concentração de extrato de levedura, glicose, extrato de malte, $\mathrm{CaCO}_{3}$, temperatura e agitação sobre o crescimento do Rhodococcus erythropolis. A partir dos resultados apresentados na Tabela 2, foi realizada uma análise estatística utilizandose ferramentas de planejamento experimental, sendo esta apresentada nos itens a seguir.

Tabela 3 - Cálculo dos efeitos e respectivos índices estatísticos.

\begin{tabular}{ccccc}
\hline & Efeito & Erro Padrão & $\begin{array}{c}\text { Teste t de } \\
\text { Student }\end{array}$ & Nível P \\
\hline Média/Interações & $\mathbf{1 , 9 3 3 1 4}$ & $\mathbf{0 , 1 6 1 4 7 5}$ & $\mathbf{1 1 , 9 7 1 7 8}$ & $\mathbf{0 , 0 0 0 0 0 0}$ \\
(1) Ext. Levedura & $\mathbf{1 , 9 1 2 1 6}$ & $\mathbf{0 , 3 4 2 5 4 0}$ & $\mathbf{5 , 5 8 2 2 8}$ & $\mathbf{0 , 0 0 0 0 6 8}$ \\
(2) Glicose & 0,36503 & 0,342540 & 1,06566 & 0,304612 \\
(3) Malte & 0,15532 & 0,342540 & 0,45343 & 0,657186 \\
(4) CaCO & $\mathbf{- 1 , 9 8 0 7 4}$ & $\mathbf{0 , 3 4 2 5 4 0}$ & $\mathbf{- 5 , 7 8 2 5 1}$ & $\mathbf{0 , 0 0 0 0 4 7}$ \\
(5) Temperatura & $\mathbf{- 0 , 8 7 0 0 4}$ & $\mathbf{0 , 3 4 2 5 4 0}$ & $\mathbf{- 2 , 5 3 9 9 7}$ & $\mathbf{0 , 0 2 3 5 7 1}$ \\
(6) Agitação & $\mathbf{1 , 6 5 4 0 9}$ & $\mathbf{0 , 3 4 2 5 4 0}$ & $\mathbf{4 , 8 2 8 9 0}$ & $\mathbf{0 , 0 0 0 2 6 8}$ \\
Interação (1) e $(\mathbf{6})$ & $\mathbf{1 , 3 4 8 1 8}$ & $\mathbf{0 , 3 4 2 5 4 0}$ & $\mathbf{3 , 9 3 5 8 3}$ & $\mathbf{0 , 0 0 1 4 9 3}$ \\
\hline
\end{tabular}


$\mathrm{Na}$ Tabela 3, têm-se os valores obtidos para os efeitos referentes aos fatores concentração de extrato de levedura, concentração de $\mathrm{CaCO}_{3}$, concentração de extrato de malte, concentração de glicose, agitação e temperatura, além de seus respectivos índices estatísticos. O crescimento foi avaliado calculando-se a diferença entre a concentração inicial e a concentração ao final de $18 \mathrm{~h}$, tempo em que o $R$. erythropolis atinge a fase estacionária.

Tabela 4 - Cálculo dos coeficientes e respectivos índices estatísticos.

\begin{tabular}{ccccc}
\hline & Coeficiente & Erro Padrão & $\begin{array}{c}-95 \% \text { Limite } \\
\text { de Confiança }\end{array}$ & $\begin{array}{c}\text { 95\% Limite } \\
\text { de Confiança }\end{array}$ \\
\hline Média/Interações & $\mathbf{1 , 9 3 3 1 4 4}$ & $\mathbf{0 , 1 6 1 4 7 5}$ & $\mathbf{1 , 5 8 6 8 1}$ & $\mathbf{2 , 2 7 9 4 7 4}$ \\
(1) Ext. Levedura & $\mathbf{0 , 9 5 6 0 7 8}$ & $\mathbf{0 , 1 7 1 2 7 0}$ & $\mathbf{0 , 5 8 8 7 4}$ & $\mathbf{1 , 3 2 3 4 1 6}$ \\
(2) Glicose & 0,182516 & 0,171270 & $-0,18482$ & 0,549854 \\
(3) Malte & 0,077659 & 0,171270 & $-0,28968$ & 0,444997 \\
(4) CaCO3 & $\mathbf{- 0 , 9 9 0 3 7 2}$ & $\mathbf{0 , 1 7 1 2 7 0}$ & $\mathbf{- 1 , 3 5 7 7 1}$ & $\mathbf{- 0 , 6 2 3 0 3 4}$ \\
(5) Temperatura & $\mathbf{- 0 , 4 3 5 0 2 2}$ & $\mathbf{0 , 1 7 1 2 7 0}$ & $\mathbf{- 0 , 8 0 2 3 6}$ & $\mathbf{- 0 , 0 6 7 6 8 4}$ \\
(6) Agitação & $\mathbf{0 , 8 2 7 0 4 7}$ & $\mathbf{0 , 1 7 1 2 7 0}$ & $\mathbf{0 , 4 5 9 7 1}$ & $\mathbf{1 , 1 9 4 3 8 5}$ \\
Interação (1) e (6) & $\mathbf{0 , 6 7 4 0 9 1}$ & $\mathbf{0 , 1 7 1 2 7 0}$ & $\mathbf{0 , 3 0 6 7 5}$ & $\mathbf{1 , 0 4 1 4 2 9}$ \\
\hline
\end{tabular}

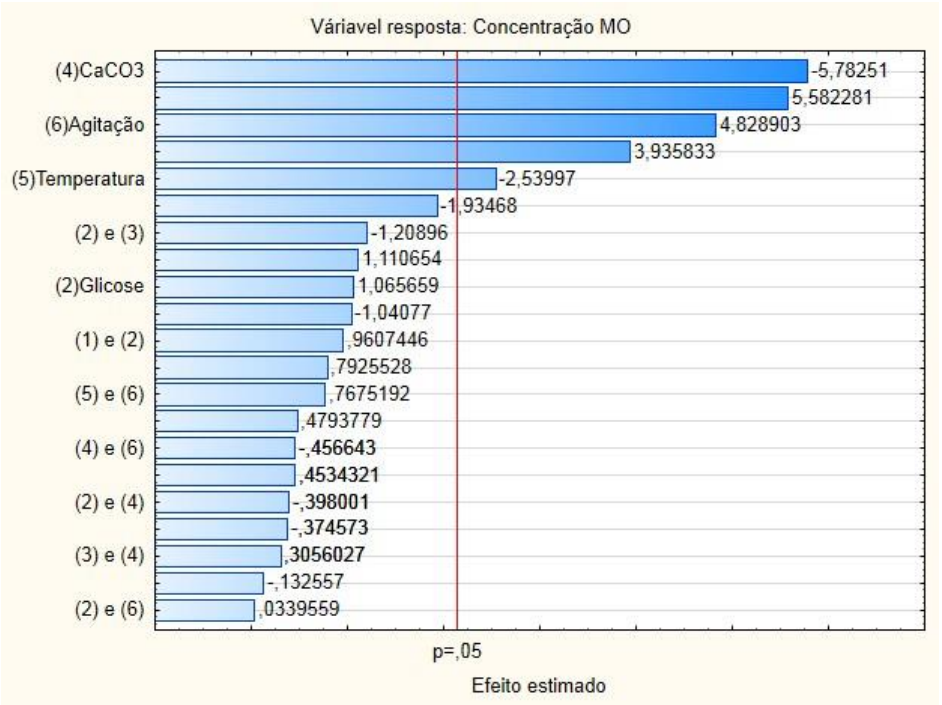

Figura 2 - Gráfico de Pareto em função dos valores estatísticos do teste t.

Verifica-se, pelas Tabelas 3 e 4 e pela Figura 2, que os termos lineares da concentração de extrato de levedura, $\mathrm{CaCO}_{3}$, agitação, temperatura e a interação entre os dois termos lineares (1) e (6) são significativos, sendo perceptível que os mais influentes são o $\mathrm{CaCO}_{3}$ juntamente com o extrato de levedura. 


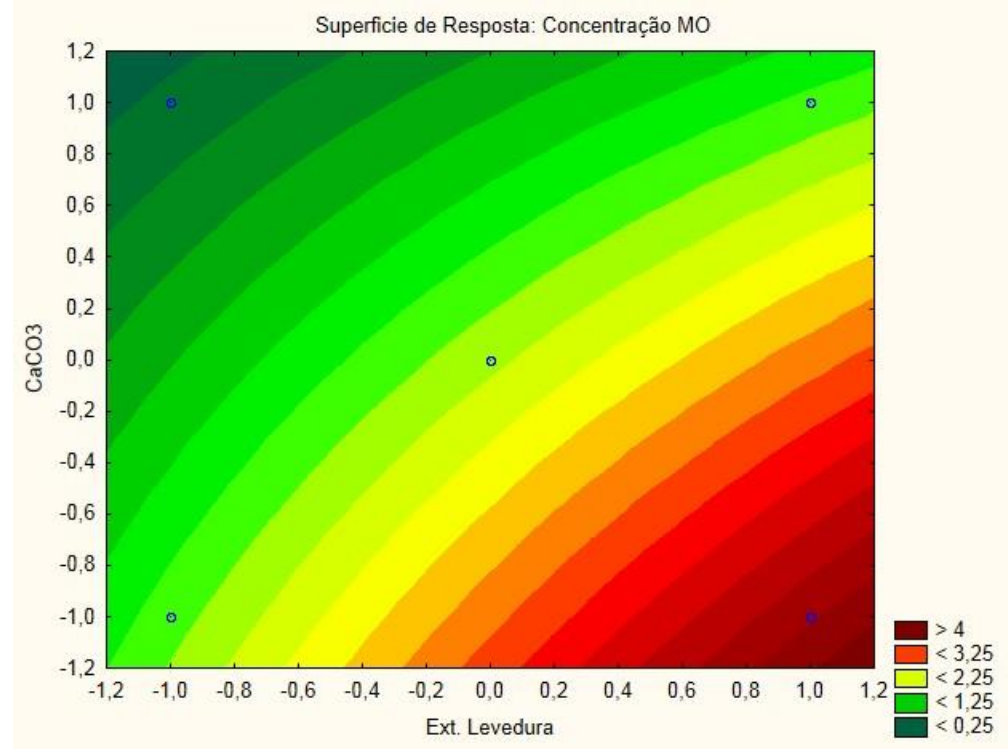

Figura 3 - Curvas de nível para os fatores de $\mathrm{CaCO}_{3}$ e extrato de levedura para o crescimento de Rhodococcus erythropolis.

A Figura 3 apresenta as curvas de nível correspondentes à superfície de resposta gerada pelo modelo linear e nota-se que, com a redução da concentração do $\mathrm{CaCO}_{3}$ e com o aumento da concentração de extrato de levedura, o crescimento celular é mais acentuado; sendo, assim, considerada a região de condição experimental ótima do processo. Essa região ótima é definida no intervalo de concentração de $\mathrm{CaCO}_{3}$ de 0,8 a $1,4 \mathrm{~g} \mathrm{~L}^{-1}$ (níveis - 1,2 a -0,6) e concentração de extrato de levedura de 4,8 a $6,4 \mathrm{~g} \mathrm{~L}^{-1}$ (níveis 0,4 a 1,2).

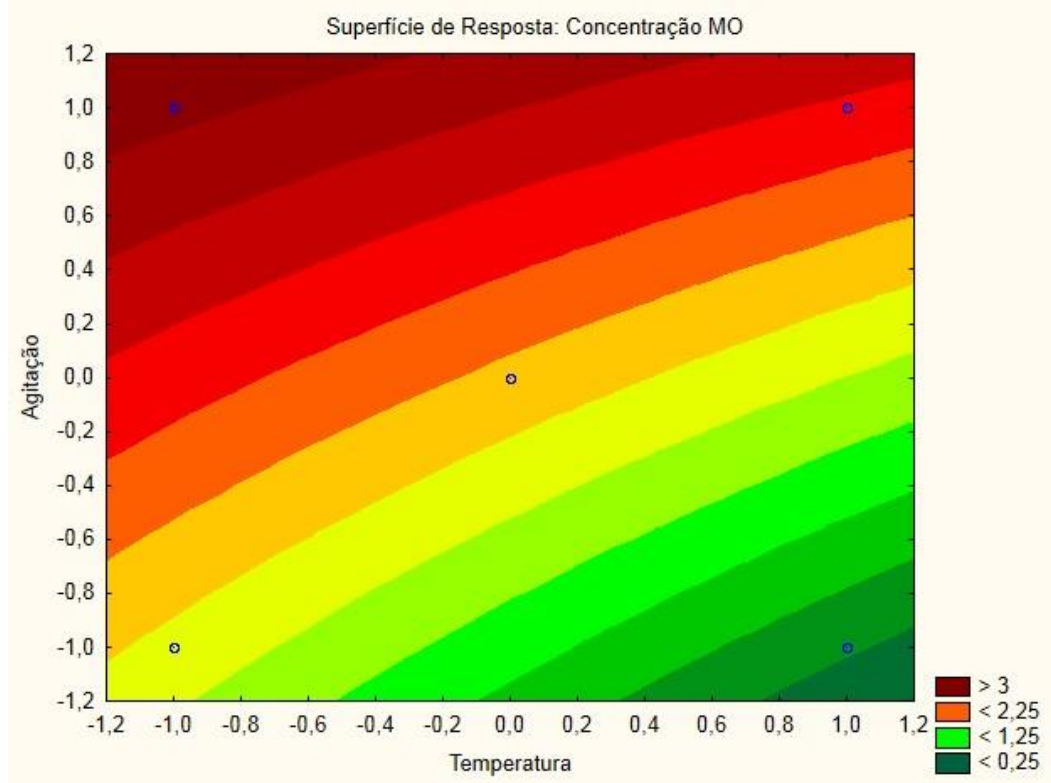

Figura 4 - Curvas de nível para os fatores de agitação e temperatura para o crescimento de Rhodococcus erythropolis. 
A Figura 4 mostra que, com a redução da temperatura e o aumento da agitação, a concentração das células, após o crescimento, encontra-se num nível máximo na região ótima de processo com agitação de 160 a 210 rpm (níveis 0,2 a 1,2) e temperatura de 23,2 a $26,4{ }^{\circ} \mathrm{C}$ (níveis $-1,2$ a -0,4).

\section{CONCLUSÃO}

Pelo planejamento experimental realizado, pôde-se concluir que as concentrações de glicose e de malte não apresentaram efeito estatístico significativo. Por esse motivo, optou-se por reduzir suas concentrações, respectivamente, de 4,0 e $10 \mathrm{~g} \mathrm{~L}^{-1}$ para 2,0 e $5 \mathrm{~g} \mathrm{~L}^{-1}$.

Foi observado que a maior influência no crescimento da bactéria estava vinculada às concentrações de levedura e $\mathrm{CaCO}_{3}$. As variáveis temperatura e agitação também foram consideradas significativas, embora em caráter menos relevante.

Este trabalho permite a minimização da realização de ensaios experimentais, priorizando o estudo de variáveis relevantes no processo.

\section{REFERÊNCIAS}

ALVES, L.; MESQUITA, E.; GÍRIO, F. M. Dessulfurização bacteriana de combustíveis fósseis. Biotecnol. Amb., v. 62, p. 3-8, 1999.

DAVOODI-DEHAGHANI, F.; VOSOUGHI, M.; ZIAEE, A. A. Biodesulfurization of dibenzothiophene by a newly isolated Rhodococcus erythropolis strain, Biores. Technol., v. 101, p. 1102-1105, 2001.

FARAH, M. A. Petróleo e seus derivados: definição, constituição, aplicação, especificações, características de qualidade. Rio de Janeiro. LTC, 2012.

GUPTA, N.; ROYCHOUDHURY, P. K.; DEB, J. K. Biotechnology of desulfurization of diesel: prospects and challenges. Appl. Microbiol. Biotechnol., v. 66, p. 356-366, 2005.

MAGHSOUDI, S.; VOSSOUGHI, S.; KHEIROLOMOOM, A.; TANAKA, E.; KATOH, S. Biodesulfurization of hydrocarbons and diesel fuels by Rhodococcus sp. strain P32C1, Biochem. Eng. J., v. 8, p. 151-156, 2001.

McFARLAND, B. L. Biodesulfurization. Ecol. Ind. Microbiol., v. 2, p. 257-264, 2000.

RODRIGUES, M. I.; IEMMA, A. F. Planejamento de experimentos e otimização de processos, Campinas, SP, 2005. 